\title{
The Hybrid Solar-RF Energy for Base Transceiver Stations
}

\author{
Cuong V. Nguyen, ${ }^{1}$ Minh T. Nguyen $\mathbb{D D}^{2}{ }^{2}$ Toan V. Quyen, ${ }^{3}$ Anh M. Le, ${ }^{4}$ and Linh H. Truong ${ }^{5}$ \\ ${ }^{1}$ Institue of Research and Development, Duy Tan University, Da Nang 550000, Vietnam \\ ${ }^{2}$ Department of Electrical Engineering, Thai Nguyen University of Technology, Thai Nguyen 24000, Vietnam \\ ${ }^{3}$ School of Electronics Engineering, Kyungpook National University, Daegu 41566, Republic of Korea \\ ${ }^{4}$ College of Electrical and Computer Engineering, National Chiao Tung University, Hsinchu 30013, Taiwan \\ ${ }^{5}$ Department of Industrial Engineering and Engineering Management, National Tsing Hua University, Hsinchu 30013, Taiwan
}

Correspondence should be addressed to Minh T. Nguyen; tuanminh.nguyen@okstate.edu

Received 15 April 2020; Revised 11 June 2020; Accepted 17 June 2020; Published 14 July 2020

Academic Editor: Yujin Lim

Copyright (c) 2020 Cuong V. Nguyen et al. This is an open access article distributed under the Creative Commons Attribution License, which permits unrestricted use, distribution, and reproduction in any medium, provided the original work is properly cited.

\begin{abstract}
The base transceiver stations (BTS) are telecom infrastructures that facilitate wireless communication between the subscriber device and the telecom operator networks. They are deployed in suitable places having a lot of freely propagating ambient radio frequency (RF) and solar energies. This paper is aimed at converting received ambient environmental energy into usable electricity to power the stations. We proposed a hybrid energy harvesting system that can collect energy from RF and solar energies at the same time. The sources are combined to provide to a significant amount, to contribute to operational expenditures that reduce energy costs, and to improve the energy efficiency of the base station sites in rural areas from the most common renewable resources since the base stations are major consumers of cellular networks. The hybrid systems are designed with circuits, simulated, and compared to show their good performance to the base stations. PSIM, PROTEUS, and MATLAB software are used to simulate for evaluating the voltage and the current output of the hybrid systems that meet the power requirements. The design and simulation results show the feasibility of our proposed method with the battery storage that can be deployed not only in real base stations but also for other electrical operated systems.
\end{abstract}

\section{Introduction}

The wireless communication system is one of the most important technologies for promoting economic and social development around the globe. Cellular systems, such as long-term evolution (LTE), are designed assuming that mobile devices connect to a base station to communicate. The base stations receive and transmit data from and to mobile users, called base transceiver stations (BTS). Since the telecom infrastructures are increasing everywhere, there are many base stations being deployed to satisfy the wireless service coverage. In particular, more than five billion new customers using wireless mobile networking services across the world were added by 2010 [1]. And according to the forum of Wireless World Research, in 2020, seven trillion wireless devices will serve seven billion people [2]. However, the extensive growth in the number of users, the new wireless products, the demand of the quality of services, and the rising service usage times result in the increased energy consumption for such networks, especially for the BTS. There are many research results considering energyefficient models for both operation and embodied energy consumption for cellular networks [3-5]. However, the world is still expecting to have further energy-efficient approaches for such networks.

Recently, the BTS are deployed in many places including rural and remote areas that may not have sustainable grid electricity systems. This motivates researchers seeking for 
TABLE 1: General levels of required power at some base transceiver stations.

\begin{tabular}{lc}
\hline Types of BTS & $\begin{array}{c}\text { Demand of power } \\
(\mathrm{kW})\end{array}$ \\
\hline GSM base station $2 / 2 / 2$ & $1.8-2.0$ \\
GSM base station 4/4/4 & $2.3-3.5$ \\
UMTS node B macro/fiber 4/4/4 & $1.7-2.0$ \\
base station & $1.6-1.8$ \\
Large WiMAX base station & \\
\hline
\end{tabular}

other resources to meet the power requirements. In general, the required power to support BTS is addressed in Table 1. In addition, the more the number of wireless communication services is, the more power would be consumed at the stations in the networks.

There are at least two strong points to motivate using green or renewable energy resources. First, this is vital to minimize the environmental impacts on climate change, caused by $\mathrm{CO}_{2}$ and other greenhouse gases in the atmosphere, emitted from the use of fossil fuels as primary resources to produce electrical energy. All network providers need to reduce electricity bills for competitive purposes. Second, when the use of energy harvesting technologies is increasing, the dependence on the electricity grid or fossil fuels will decrease significantly. This has led to a reduction in operating costs for stations aimed at reducing service costs. So, energy harvesting technologies are considered to support the networks, not only at the stations but also at other lowenergy consumption devices.

Energy harvesting $(\mathrm{EH})$ or energy scavenging is a very promising technology for applications where batteries are impractical and/or power grid networks are not sustainable. The energy is achieved from ambient sources, such as solar, vibration, thermal, wind, and radio frequency (RF). The amount of harvested energy strongly depends on the performance, specific materials, and ambient resources as shown in Table 2 [6]. Based on that, many applications have applied different $\mathrm{EH}$ technologies to improve their performance and service quality. Currently, the harvested energy can support many electricity-operated systems, such as wireless sensor networks $[6,7]$, low-power consumption devices, robots, unmanned aerial vehicles [8-10], and even wheelchairs [11] to prolong the operating time. EH technologies can be combined to collect energy not only from a single source but also from some suitable ambient sources, called hybrid, to provide sufficient power for specific applications $[12,13]$.

In this paper, we propose a hybrid EH system to power the BTS as a backup system after the batteries and the generators may not perform well. As shown in Figure 1, the hybrid system can work together with other backup systems to provide the best solution for powering the BTS. The two most common resources such as RF and solar energies are collected to support the system. Different from the existing work, the proposed method provides a sufficient amount of energy to support the working BTS as well as the sustainable grid in a good condition. We design the systems in different
TABLE 2: Energy scavenging from different resources [6].

\begin{tabular}{lcc}
\hline Energy sources & Conditions & Performance \\
\hline Solar & Outdoor & $7500 \mu \mathrm{W} / \mathrm{cm}^{2}$ \\
Solar & Indoor & $100 \mu \mathrm{W} / \mathrm{cm}^{2}$ \\
RF & $\mathrm{WiFi}$ & $0.001 \mu \mathrm{W} / \mathrm{cm}^{2}$ \\
RF & $\mathrm{GSM}$ & $0.1 \mu \mathrm{W} / \mathrm{cm}^{2}$ \\
Vibration & $1 \mathrm{~m} / \mathrm{s}^{2}$ & $100 \mu \mathrm{W} / \mathrm{cm}^{3}$ \\
Thermal & $\Delta T=5^{\circ} \mathrm{C}$ & $60 \mu \mathrm{W} / \mathrm{cm}^{2}$ \\
\hline
\end{tabular}

cases of using the stand-alone $\mathrm{EH}$ and hybrid $\mathrm{EH}$ and compare the effectiveness of the systems. All the circuits are designed and run to provide promising results. The outcomes are shown to be sufficient to power the BTS that supports the communication networks working well in good conditions.

The rest of the paper is addressed as follows. Section 2 provides the system model. Section 3 presents and analyzes the components of the hybrid solar-RF power supply system. The simulation and results are mentioned in Section 4. Finally, conclusions and future work are addressed in Section 5.

\section{System Model}

In this section, the full picture of the hybrid system is modeled with all components for the purpose of harvesting energy to support the BTS. Figure 2 shows the model system of hybrid power. The hybrid system consists of main components such as the solar cells, the RF harvester, a common DC bus, the stabilizer system, and the backup batteries. The solar energy system is composed of the photovoltaic (PV) arrays. They apply the maximum power point tracking (MPPT) method to adjust the duty cycle of the boost converter to achieve high voltage.

The RF energy is received by the antenna from the ambient environment. The main function of the matching circuit is to step up the input voltage of the rectifier and diminish the transmission loss from the antenna to the rectifier. The rectifier is used to convert AC-DC voltage. After that, the voltage outputs of the solar cells and RF energy will be supplied to the boost converter to step up these voltages to a higher level. The stabilizer system will receive the output voltage of the boost converter and produce a suitable voltage for the BTS system. The backup battery system is used to store the power when the hybrid system is at the peak power point and then used when the power system is not available.

\section{The Proposed Hybrid System}

In this section, all the main components are addressed in detail with the related functions and equations.

3.1. The DC-DC Boost Converter. The DC-DC boost converter is used to step up the input voltage to the higher voltage [14]. The boost converter configuration includes the primary input power, an inductor, the MOSFET transistor, 


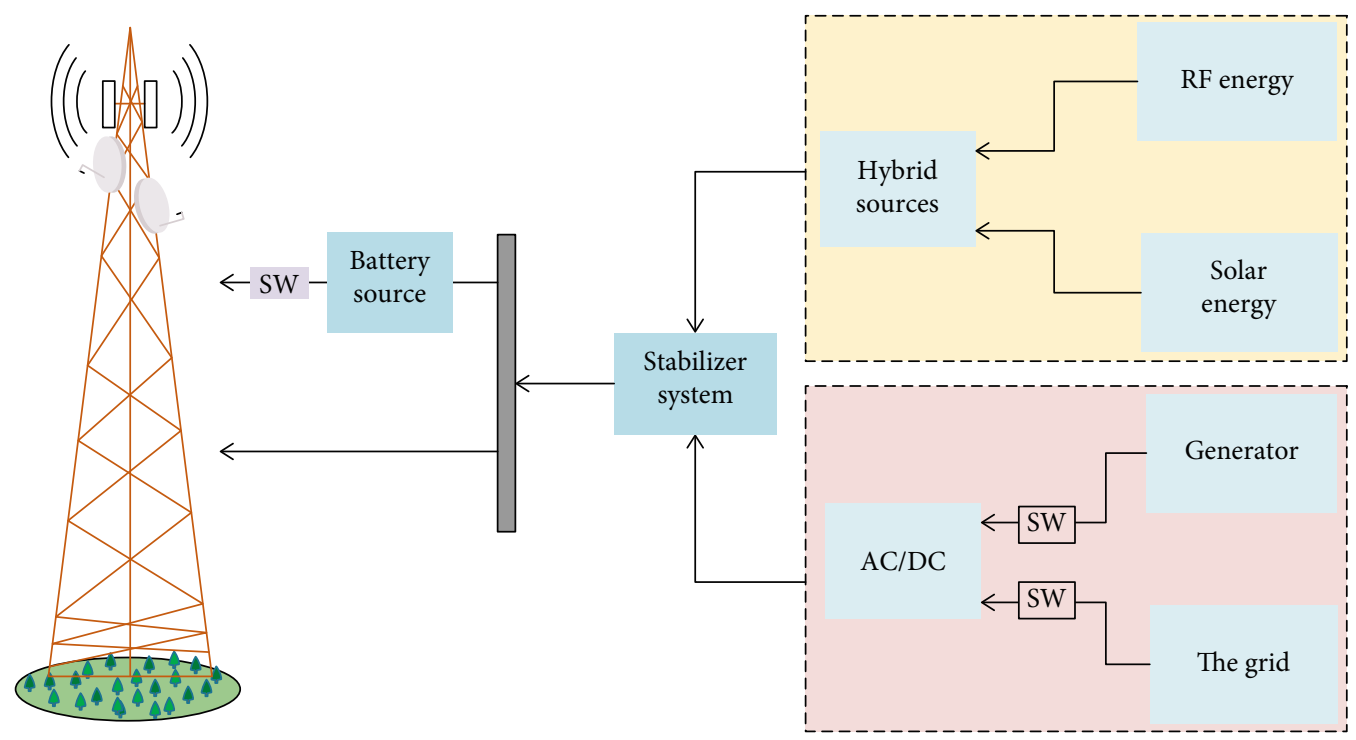

FIGURE 1: Hybrid energy harvesting system model with solar and RF energy.

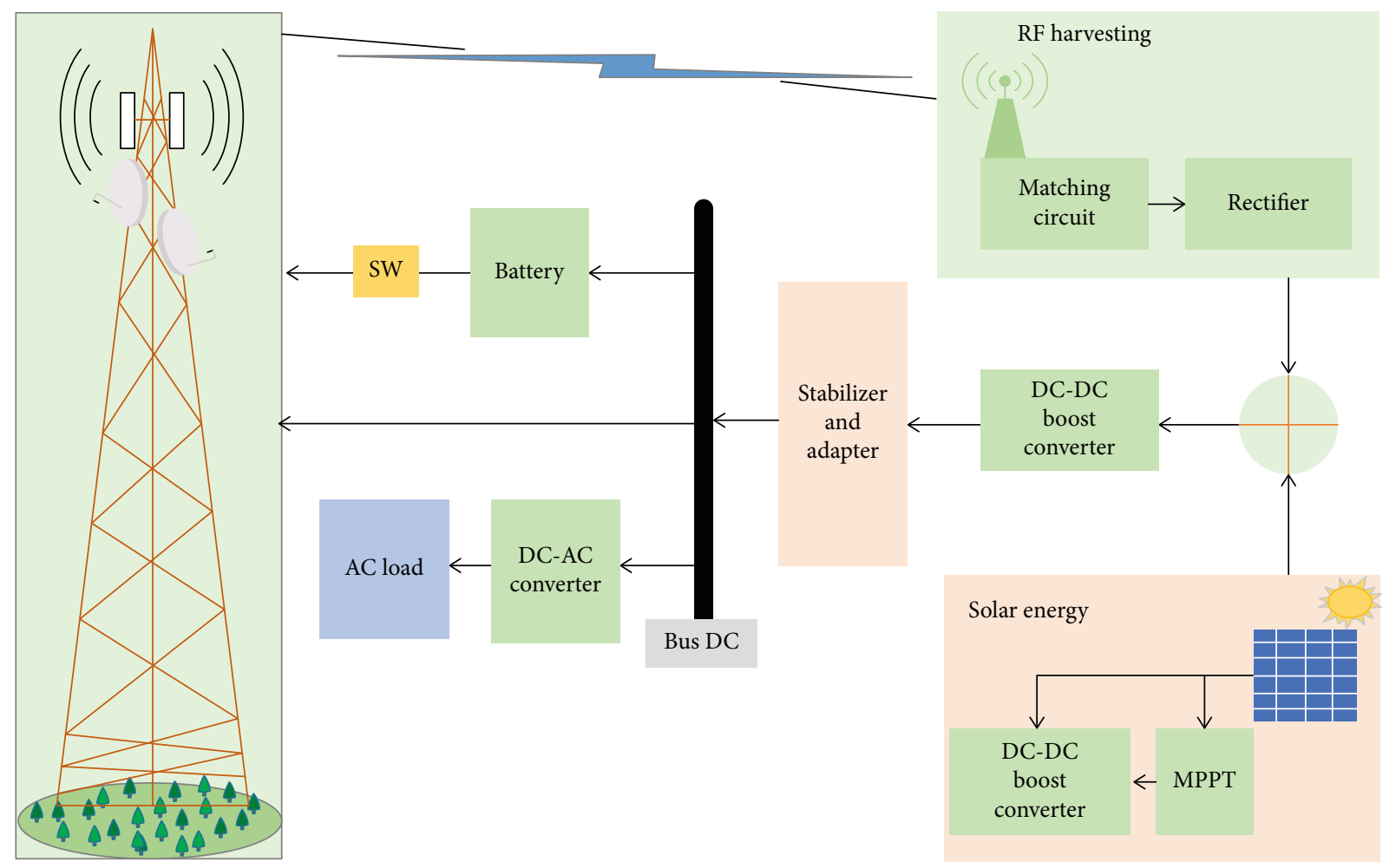

FIgURE 2: The hybrid system model with all components.

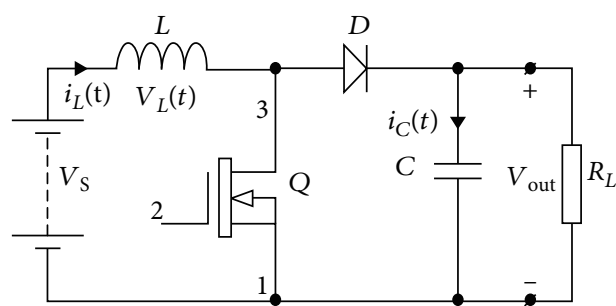

FIgURE 3: The scheme of the boost converter. the capacitor, the diode, and the load, as shown in Figure 3. The MOSFET transistor turns on and turns off at a certain frequency and certain duty cycle. During MOSFET ON, the inductor will store the current flowing through it, and the diode prevents unnecessary discharge of the capacitor to the source. During MOSFET OFF, the capacitor will be fully charged by the source and provides power to the load later. The boost converter has two modes which are MOSFET transistor on and MOSFET transistor off. Here, $V_{\mathrm{s}}$ is the source 


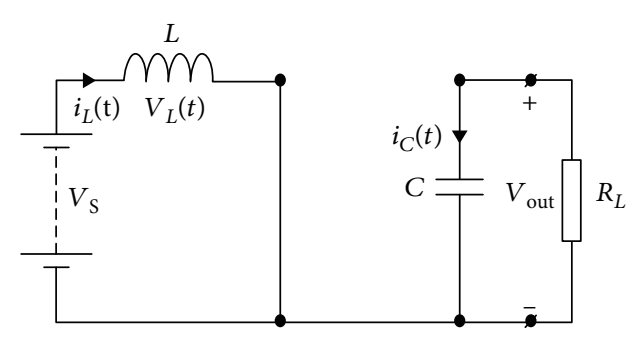

(a) MOSFET ON

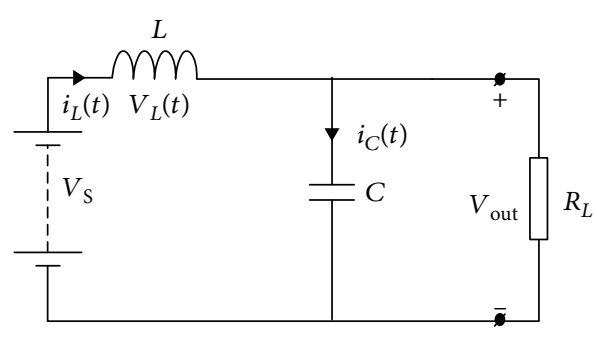

(b) MOSFET OFF

FIGURE 4: The MOSFET mode of the boost converter.

voltage of the boost converter, $V_{\text {out }}$ is the output voltage, $D_{\text {on }}$ is the on-percentage of the time, $L$ is the inductance of the inductor, and $D_{\text {off }}$ is the off-duty cycle. The $t_{\text {on }}$ and $t_{\text {off }}$ are the time interval of MOSFET ON or OFF, respectively.

The relationship between input and output voltage is as follows:

$$
\frac{V_{\text {out }}}{V_{\mathrm{s}}}=\frac{1}{D_{\text {off }}} .
$$

Equally, the off-duty cycle may be expressed as follows:

$$
D_{\text {off }}=1-D_{\text {on }} \text {. }
$$

The effect of the inductor and the duty cycle is shown in the following formula:

$$
\frac{V_{\mathrm{s}}}{L} t_{\mathrm{on}}=\frac{V_{\mathrm{out}}-V_{\mathrm{s}}}{L} t_{\mathrm{off}}
$$

The MOSFET is like a conductor (the MOSFET transistor turns on), as shown in Figure 4(a). The input current is only going to flow to the inductor. The whole source power is stored in this inductor as indicated in Equation (5). During this period, the voltage is constant, but the current increases. Hence, the storing power of the inductor is gradually increasing.

$$
V_{L}=V_{\mathrm{s}},
$$

when the MOSFET transistor turns off, as shown in Figure 4(b). The supplying power is not only the input power but also the storing power of the inductor during MOSFET ON mode. Based on the energy conversion theory, when the supplying power rises, the power to provide the load will also increase as indicated in Equation (6). The supplying power will charge for the capacitor and supply to the load at the same time.

$$
V_{\text {out }}=V_{\mathrm{s}}+V_{L}
$$

3.2. The Buck Converter. Figure 5 depicts the scheme of the buck converter. The fundamental difference between the boost converter and the buck converter is the position variation of the three main electrical components such as the MOSFET transistor, inductor, and diode. This changes

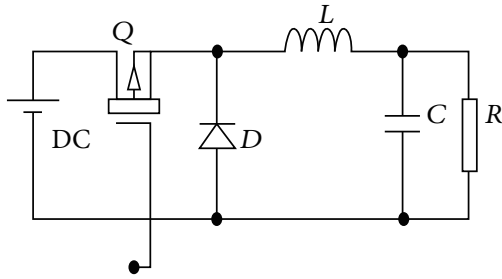

FIgURE 5: The scheme of the buck converter.

the feature of this circuit that converts the high voltage into low voltage [15]. The MOSFET transistor turns on and turns off at a certain frequency and certain duty cycle. An inductor $L$ limits the flowing current to prevent the capacitor, but when the MOSFET changes from off to on, the current through the inductor cannot change instantaneously. The inductor will force the current to keep flowing through the switch even after we open it, which is an extremely dangerous phenomenon, so the diodes are used to keep the current flowing in the different path when the MOSFET is off. Last, the capacitor is used to store the voltage. The buck converter has two modes which are MOSFET transistor on and MOSFET transistor off. Here, $V_{\mathrm{s}}$ is the source voltage of the boost converter, $V_{\text {out }}$ is the output voltage, $D_{\text {on }}$ is the on-percentage of the time, $L$ is the inductance of the inductor, and $D_{\text {off }}$ is the off-duty cycle.

The effect of the inductor and the duty cycle is shown in the following formula:

$$
\begin{gathered}
\frac{V_{\mathrm{s}}-V_{\text {out }}}{L} t_{\text {on }}=\frac{V_{\text {out }}}{L} t_{\text {off }}, \\
\frac{V_{\text {out }}}{V_{\mathrm{s}}}=\frac{t_{\text {on }}}{t_{\text {on }}+t_{\text {off }}}=\frac{t_{\text {on }}}{T_{\mathrm{s}}}=D_{\text {on }} .
\end{gathered}
$$

When the switch is off, the input current does not flow anywhere. The capacitor's current will flow through the load, the diode, and the inductor. This current keeps flowing through the inductor when the switch is off which helps prevent the dangerous phenomena from the instantaneously increasing current.

The off-duty cycle is expressed as

$$
D_{\text {off }}=1-D_{\text {on }} \text {. }
$$




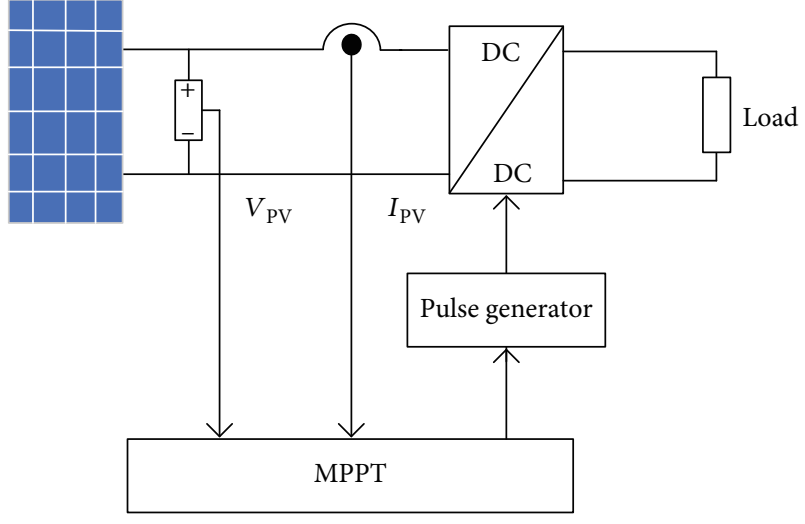

(a) The block diagram

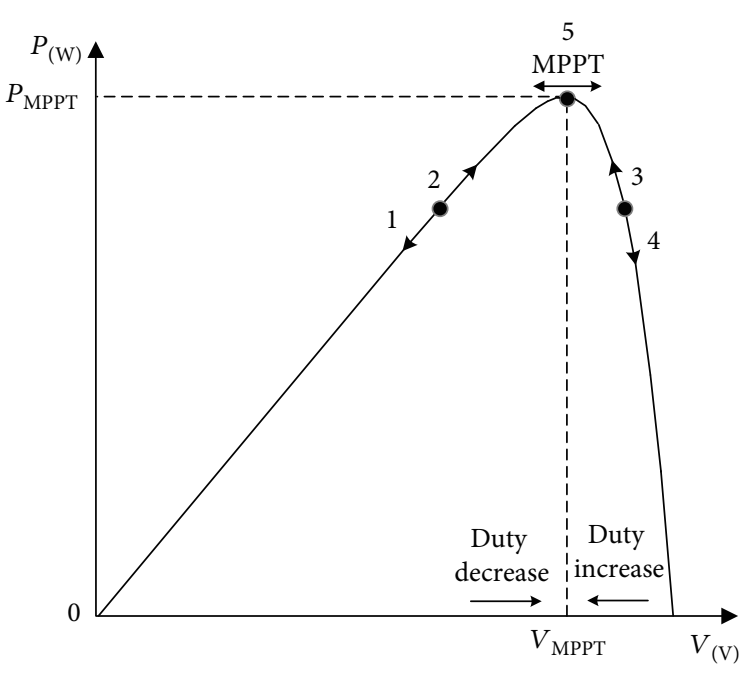

(b) The nonlinear characteristic

FIgURE 6: The perturb and observe (P\&O) algorithms in the MPPT controller.

TABle 3: The principle of operation for the $\mathrm{P} \& \mathrm{O}$ algorithms in MPPT.

\begin{tabular}{lcc}
\hline Status & Condition & Actions \\
\hline 1 & $\Delta P_{\mathrm{PV}}<0, \Delta V_{\mathrm{PV}}<0$ & Duty decrease \\
2 & $\Delta P_{\mathrm{PV}}>0, \Delta V_{\mathrm{PV}}>0$ & Duty decrease \\
3 & $\Delta P_{\mathrm{PV}}>0, \Delta V_{\mathrm{PV}}<0$ & Duty increase \\
4 & $\Delta P_{\mathrm{PV}}<0, \Delta V_{\mathrm{PV}}>0$ & Duty decrease \\
5 & $\Delta P_{\mathrm{PV}}=0, \Delta V_{\mathrm{PV}}=0$ & No action \\
\hline
\end{tabular}

3.3. MPPT Algorithms. The basic and adaptive MPPT algorithms have been studied for distributed photovoltaic systems to maximize the energy production of a photovoltaic module. MPPT using a fixed step size, such as perturb and observe $(\mathrm{P} \& \mathrm{O})$ and incremental conductance, suffer from a trade-off between tracking accuracy and tracking speed. In this paper, we use $\mathrm{P} \& \mathrm{O}$ algorithms. $\mathrm{P} \& \mathrm{O}$ algorithms operate on the fundamental principle that the variation $\left(\Delta P_{\mathrm{PV}}\right)$ of $\mathrm{PV}$ voltage $\left(V_{\mathrm{PV}}\right)$ and the variation $\left(\Delta P_{\mathrm{PV}}\right)$ of $\mathrm{PV}$ power $\left(P_{\mathrm{PV}}\right)$ become zero at the maximum power point (MPP). The principle of MPPT algorithms is shown in Figure 6 and Table 3.

3.4. The Voltage Multiplier. The voltage multiplier (VM) converts the AC input source from a lower voltage to a higher DC voltage. The VM includes diodes and a capacitor. Because the input is an AC source, the operation is divided into two loops, as shown in Figure 7.

In the first loop, the current flows through the diode $D_{1}$ and charges for the capacitor $C_{1}$, but the current cannot charge for the diode $C_{2}$ because the current $D_{1}$ is blocked by the diode. After that, to the second loop, the current flows to the $C_{1}$ to the diode $C_{2}$ and charges for the diode $C_{2}$, but the current is blocked by the $\operatorname{diode} C_{1}$. The output voltage equals the voltage of the diode $C_{2}$, as shown in Equation (8), because the $\operatorname{diode} C_{1}$ is discharged by the direction of the current. The higher the numbers of the stages have, the higher the output voltage can achieve [16].

\section{Analysis and Discussions}

In this work, the proposed power system supplies power $48 \mathrm{~V}$ and $52 \mathrm{~A}$ to the BTS system. Because the settling time is inversely proportional to the output values, we need to trade off between the settling time and the output values. Our target harvested $20 \mathrm{VDC}$ RF energy after using the voltage multiplier and 100 VDC solar energy after using the boost converter within the proper settling time. The current of the hybrid system is less than $2 \mathrm{~A}$, but the desired current is much more than this result. Therefore, the output values of the hybrid system need to step up to great values in order to achieve a high output current. To create the $52 \mathrm{~A}$ and 48 VDC output values, the output values of the hybrid solar-RF energy are processed by the boost converter and stabilizer system. The DC-DC boost converter is used to step up the voltage to $400 \mathrm{VDC}$. The stabilizer and adapter system makes the desired current and voltage output stable. The problems are simulated and solved in PSIM, PROTEUS, and MATLAB Simulink.

4.1. The Hybrid Solar-RF Energy Harvesting. The solar and $\mathrm{RF}$ energy is abundant in the surrounding environment at the base transceiver station (BTS) system. Hence, the hybrid renewable energy harvesting includes solar energy and RF energy to leverage these plentiful sources. The hybrid system is able to harvest $20 \mathrm{VDC}$ from RF energy and $100 \mathrm{VDC}$ from solar cells.

4.2. RF Energy Harvesting. The voltage multipliers (VM) are used to convert AC to DC voltage and step up to higher voltage. The stage numbers of the VM directly affect the output voltage. The higher the stage numbers of the VM have, the higher the output voltage achieves [8], but the VM drawback is the delay time. In the RF system, we choose 


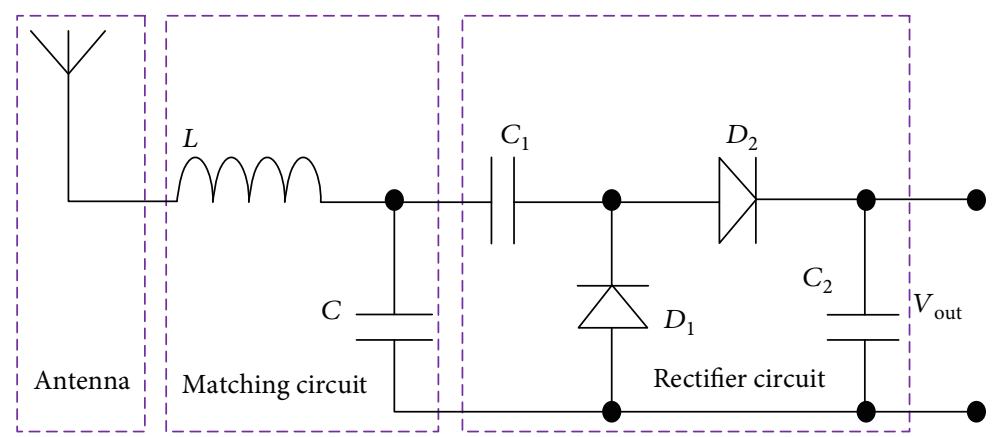

Figure 7: The scheme of the RF energy harvesting.

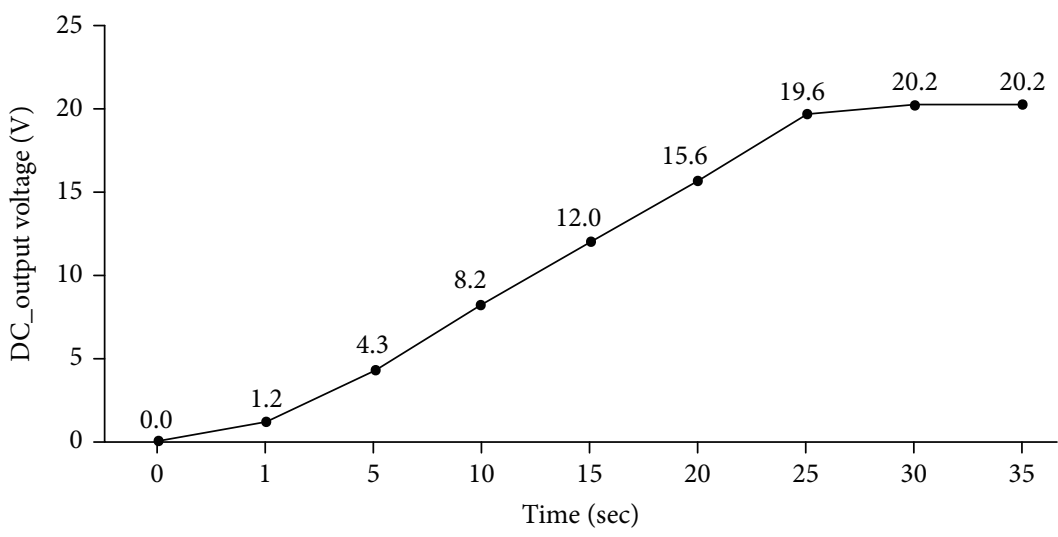

FIGURE 8: The output voltage of the RF energy system.

the 7-stage voltage multipliers to boost the harvesting voltage to the desired values. With the 7-stage VM, the longer the time the voltage multipliers take, the higher the output voltage is able to achieve [17]. In order to balance between the output voltage and the delay time, our target gets 20 DC voltage from the RF energy system. In Figure 8, the output voltage reaches $20 \mathrm{VDC}$ in just 25 seconds, so the results are satisfying for both the desired output value and the delay time. Hence, the RF energy meets 20 DC voltage, approximately $20 \%$ of the energy of the hybrid system.

4.3. Solar Energy Harvesting. We assume that the voltage of the solar panel harvested from the ambient environment is 20 VDC. The harvesting voltage needs to be boosted to the higher voltage by the solar system. The solar system comprises the boost converter and maximum power point tracking (MPPT) to step up the voltage to the desired values with high efficiency [18-20]. Figure 9 presents the output values of the stand-alone solar PV system. The output voltage approaches 100 volts and the output current approaches $1.2 \mathrm{~A}$ for about 6 seconds, and those values are maintained until the end of the simulation. Approximately $80 \%$ of the energy of the hybrid system is powered by the solar PV system.

4.4. Boost Converter. The original voltage and current harvested from the ambient resources are not suitable to supply for BTS systems that require high current and low DC voltage. In order to have a high output current, the input voltage and current will be stepped up to great values. By using the boost converter, the harvested power of $120 \mathrm{VDC}$ will be boosted to $400 \mathrm{VDC}$ and $82 \mathrm{~A}$.

In Figures 10(a) and 10(b), the output values are great and the time to reach these values is short. However, the disadvantages of the boost converter are the fluctuated outputs. In Figure 10(a), the voltage oscillates from 350 to 450 VDC, and the current also oscillates as shown in Figure 10(b). Obviously, the output values of the boost converter have significant fluctuations that cause negative effects on power systems. In order to address this problem, the stabilizer system is used to generate a suitable voltage and current for the BTS system.

4.5. Stabilizer and Adapter System. The main functions of the stabilizer system are to create the desired voltage and current with a steady output to supply the base transceiver station (BTS) system. The stabilizer includes the buck converter and the controller. The buck converter is used to step down the voltage, but it is difficult to get to the desired output values without the controlling part. The controller is the determinant to exactly create the desired outputs by controlling MOSFET's switching of the buck converter.

By utilizing the stabilizer system, the $400 \mathrm{VDC}$ voltage and $100 \mathrm{~A}$ current are stepped down to $48 \mathrm{VDC}$ and $52 \mathrm{~A}$, 


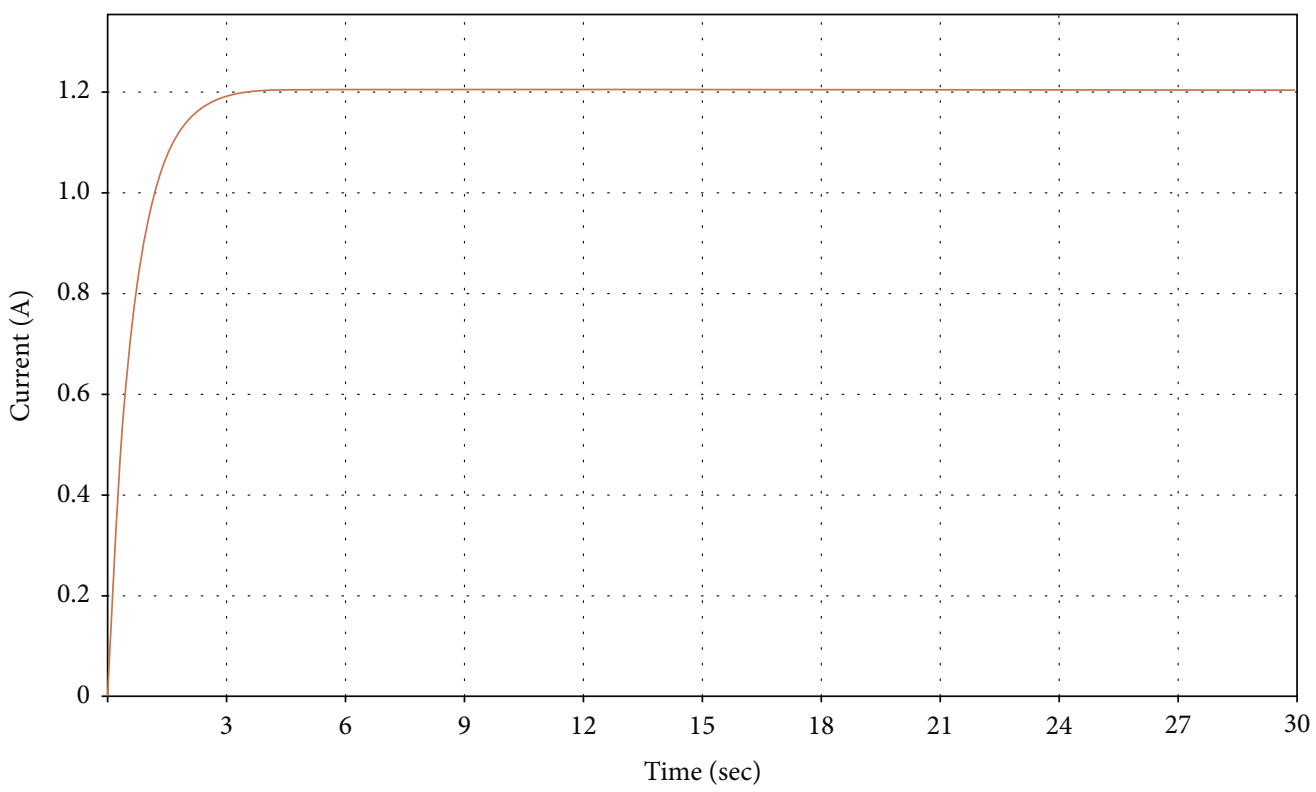

(a) The output current

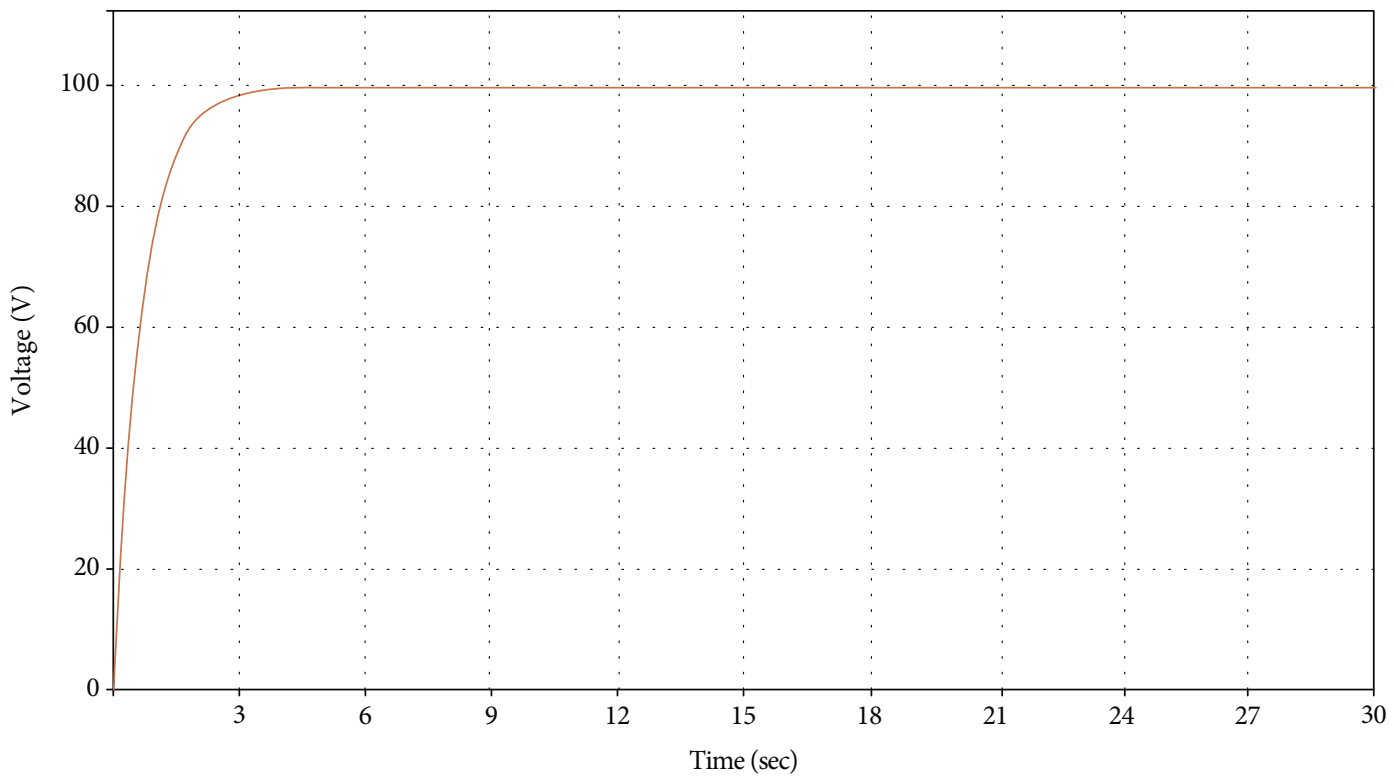

(b) The output voltage

Figure 9: The output of the solar cells.

as shown in Figure 11, and the time for reaching these output values is approximately one minute. The settling time of the stabilizer's outputs is dependent on the output values of the boost converter. The higher the output values of the boost converter are produced, the shorter the settling time of the stabilizer's outputs is taken.

4.6. Discussion. The amount of RF at the BTS is plentiful, and the generating energy is quite large to contribute to the system. The BTS power is supplied by the two main sources and two backup sources, which are the hybrid solar-RF energy, grid sources, generator, and batteries. Because the BTS system has some different sources, the supplying power system needs to be operated versatilely to avoid interruption in providing power to the loads. The supplying power system is divided into three modes depending on the source priority to supply power to loads. The hybrid energy source is the top priority and then the grid source. The batteries are only used when the above two sources are not available to meet power. During the normal mode, the first source choice is the hybrid energy system (HES), supplying power to the BTS system and charging batteries at the same time. When the HES is not sufficient to satisfy the power demand, the energy shortage will be supplied by the grid which is considered just a backup. During the unusual case, when the grid is not available and the HES is also not sufficient, the BTS power is supplied by the batteries. During battery usage, if the grid or the HES is available, the BTS system and batteries are 


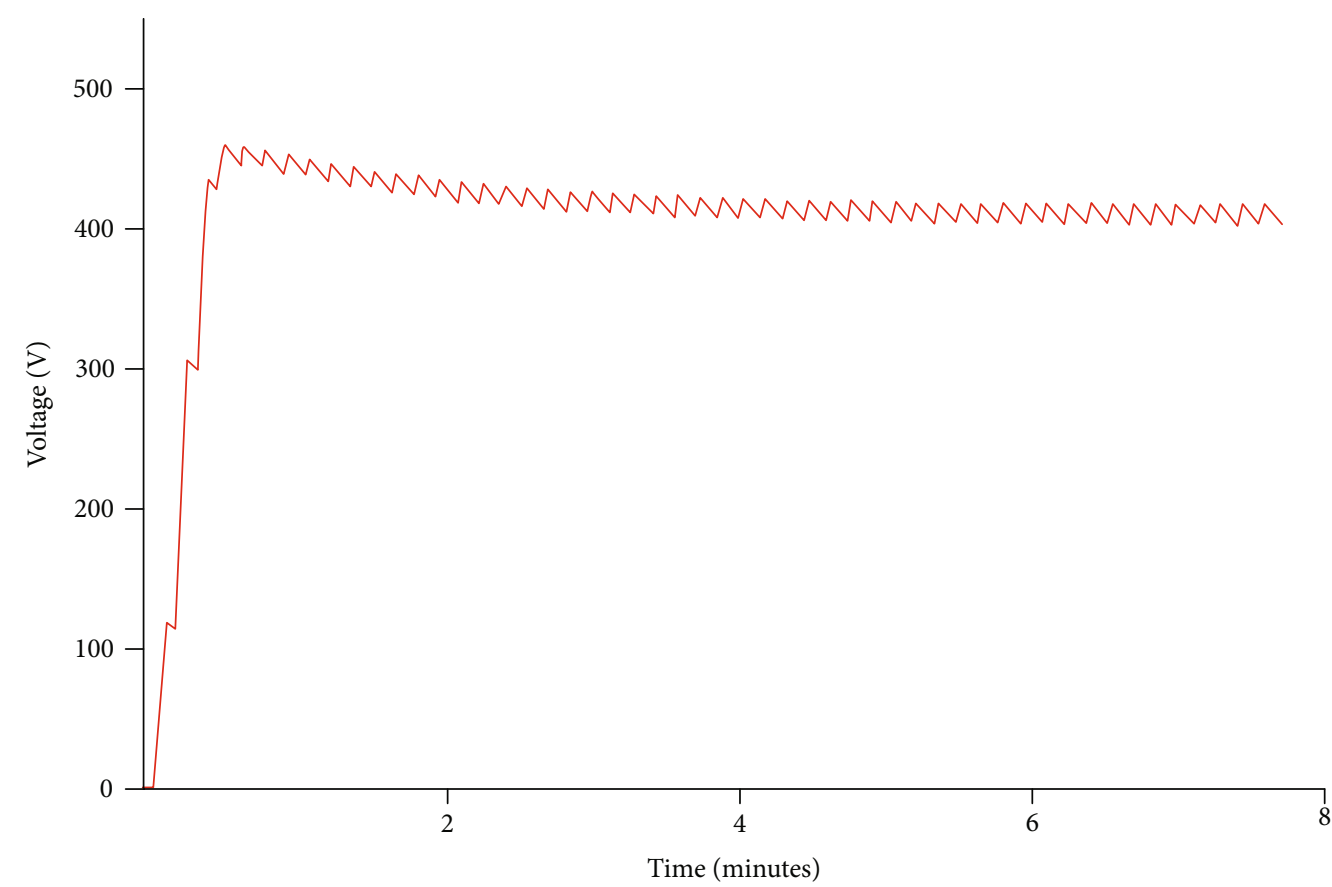

(a) The output voltage

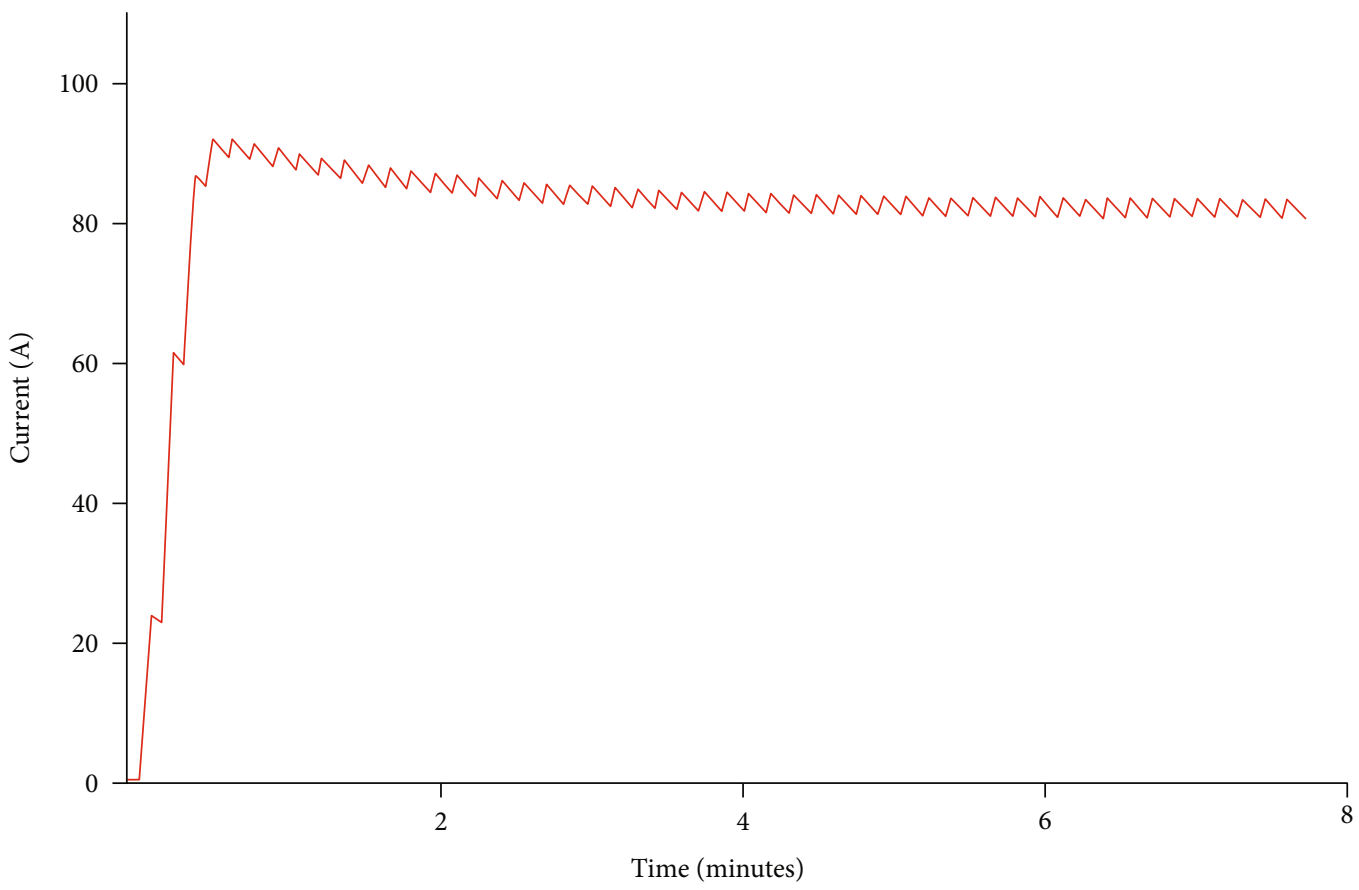

(b) The output current

FIgURE 10: The output of the boost converter.

provided by the grid or the HES. In the last case, if the batteries run out, the generator is used to supply power for the system.

\section{Conclusions and Future Work}

In this work, we propose a new hybrid energy harvesting system for a specific purpose such as powering the base stations in communication networks. The hybrid solar-RF energy sys- tem is designed, simulated, and calculated to evaluate the outcomes. It is shown that the proposed system can supply $52 \mathrm{~A}$ and $48 \mathrm{VDC}$ to the BTS that would be sufficient. The hybrid system powering $2.5 \mathrm{~kW}$ power helps mitigate the huge power supplied by the grid. Therefore, the proposed power system contributes positively to both the environment and economic aspects. The results show promise that it could be practically deployed to relax the burden of energy supplies. This also 


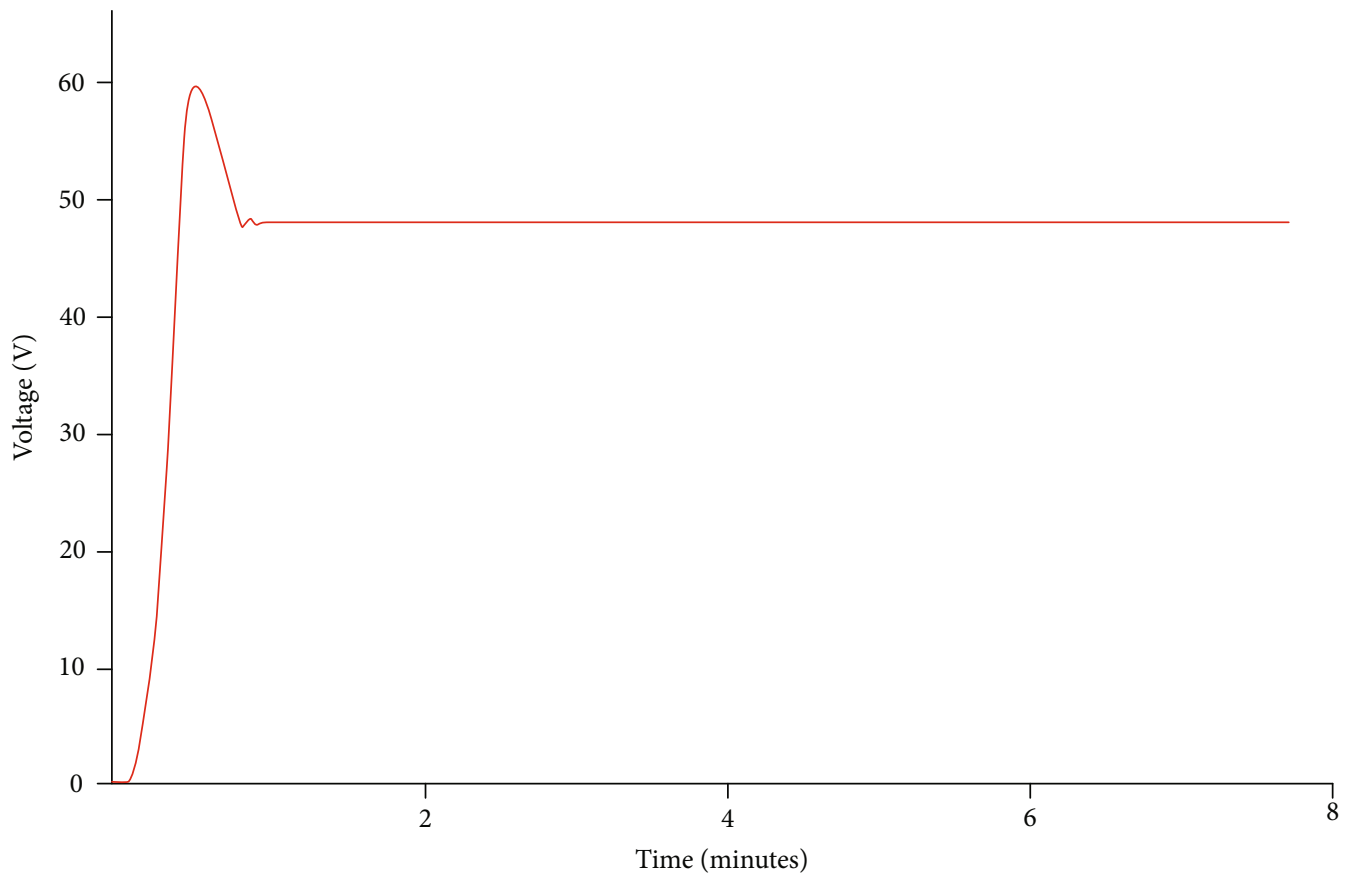

(a) The output voltage

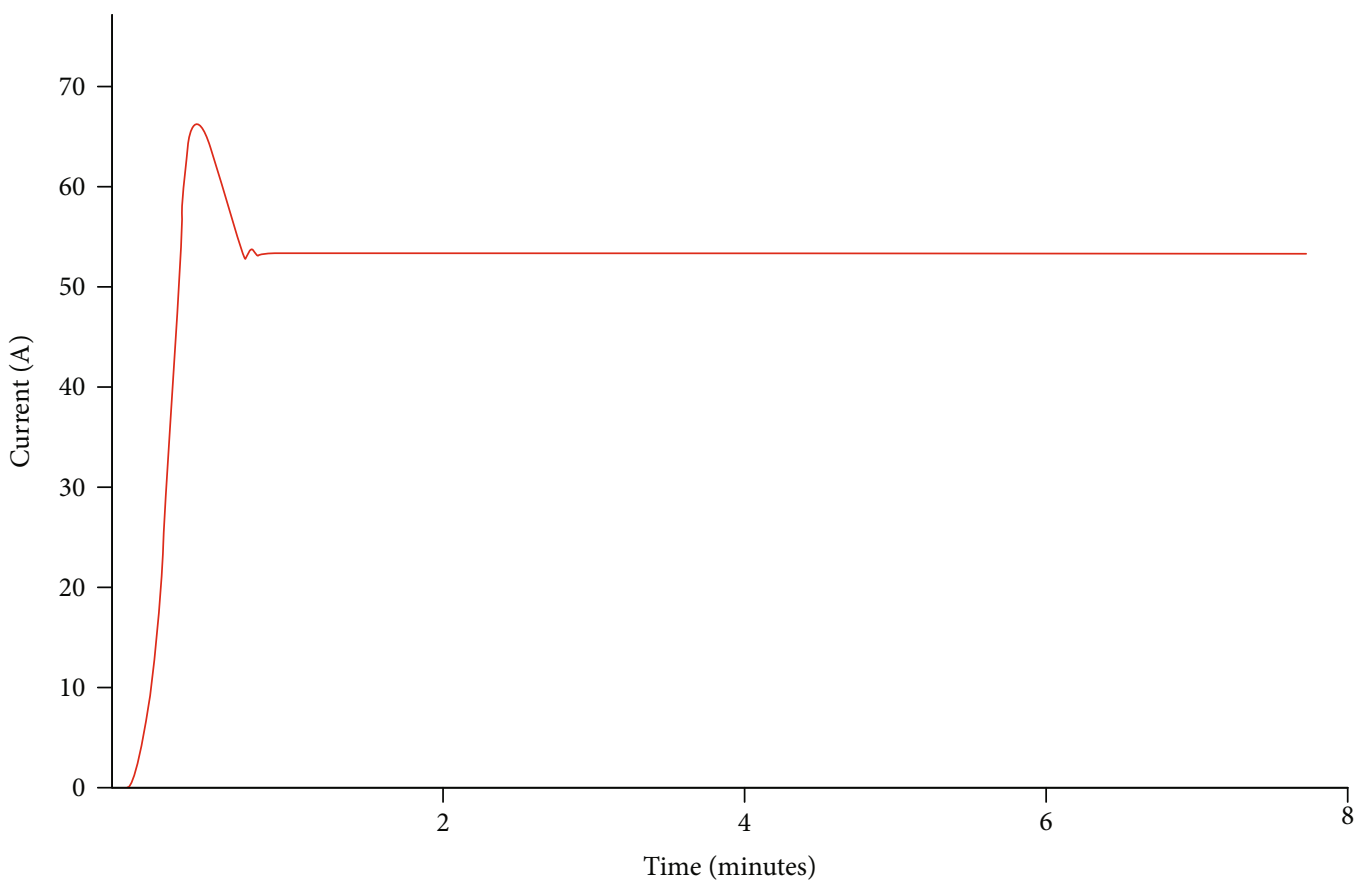

(b) The output current

FIGURE 11: The output of the stabilizer.

supports mobile BTS working in different fields where need for communication capacity is increasing.

Since the management of the source power has not been mentioned yet, that would be the next steps to improve the systems. Besides, it is possible to improve the efficiency of the boost converter and buck converter by utilizing the fuzzy and particle swarm optimization methods to control the duty cycle of the MOSFET. Last, we are going to alleviate power dissipa- tion during the on and off modes of the MOSFET by changing the hard switching to soft switching. A soft-switched device turns on and off at zero or nearly zero voltage or current.

\section{Data Availability}

Data used in this study are all in the manuscript. We are willing to provide all the data if needed. 


\section{Conflicts of Interest}

The authors declare that there are no conflicts of interest regarding the publication of this paper.

\section{Acknowledgments}

The authors would like to thank Thai Nguyen University of Technology (TNUT), Vietnam, for the support.

\section{References}

[1] N. Faruk, M. Y. Muhammad, O. Bello, A. Abdulkarim, A. John, and M. Gumel, "Energy conservation through site optimization for mobile cellular systems (base transceivers station optimization)," Epistemics in Science, Engineering and Technology, vol. 2, no. 1, pp. 26-33, 2012.

[2] K. David, D. Dixit, and N. Jefferies, "2020 vision," IEEE Vehicular Technology Magazine, vol. 5, no. 3, pp. 22-29, 2010.

[3] I. Humar, X. Ge, L. Xiang, M. Jo, M. Chen, and J. Zhang, "Rethinking energy efficiency models of cellular networks with embodied energy," IEEE Network, vol. 25, no. 2, pp. 40-49, 2011.

[4] Z. Hasan, H. Boostanimehr, and V. K. Bhargava, "Green cellular networks: a survey, some research issues and challenges," IEEE Communications Surveys \& Tutorials, vol. 13, no. 4, pp. 524-540, 2011.

[5] A. Spagnuolo, A. Petraglia, C. Vetromile, R. Formosi, and C. Lubritto, "Monitoring and optimization of energy consumption of base transceiver stations," Energy, vol. 81, pp. 286-293, 2015.

[6] M. T. Nguyen, "Energy harvesting in wireless sensor networks: benefits and challenges," ICSES Interdisciplinary Transactions on Cloud Computing, IoT, and Big Data, vol. 4, no. 1, pp. 1-3, 2020.

[7] F. K. Shaikh and S. Zeadally, "Energy harvesting in wireless sensor networks: a comprehensive review," Renewable and Sustainable Energy Reviews, vol. 55, pp. 1041-1054, 2016.

[8] V. T. Vu, T. V. Quyen, L. H. Truong, A. M. Le, C. V. Nguyen, and M. T. Nguyen, "Energy efficient approaches in wireless sensor networks," ICSES Transactions on Computer Networks and Communications, vol. 6, no. 1, pp. 1-10, 2020.

[9] C. Van Nguyen, T. Van Quyen, A. M. Le, L. H. Truong, and M. T. Nguyen, "Advanced Hybrid Energy Harvesting Systems for Unmanned Ariel Vehicles (UAVs)," Advances in Science, Technology and Engineering Systems Journal, vol. 5, no. 1, pp. 34-39, 2020.

[10] M. T. Nguyen, C. V. Nguyen, L. H. Truong et al., "Electromagnetic field based wpt technologies for uavs: a comprehensive survey," Electronics, vol. 9, no. 3, p. 461, 2020.

[11] C. V. Nguyen, M. T. Nguyen, T. V. Quyen et al., "Hybrid solarRF energy harvesting systems for electric operated wheelchairs," Electronics, vol. 9, no. 5, p. 752, 2020.

[12] S. A. Chowdhury and S. Aziz, "Solar-diesel hybrid energy model for base transceiver station (bts) of mobile phone operators," in 2nd International Conference on the Developments in Renewable Energy Technology (ICDRET 2012), pp. 1-6, Dhaka, Bangladesh, 2012.

[13] T. V. Quyen, C. V. Nguyen, A. M. Le, and M. T. Nguyen, "Optimizing hybrid energy harvesting mechanisms for
UAVs," EAI Endorsed Transactions on Energy Web, vol. 7, no. $28,2020$.

[14] P. Sanjeevikumar and K. Rajambal, "Extra-high-voltage DCDC boost converters topology with simple control strategy," Modelling and simulation in Engineering, vol. 2008, Article ID 593042, 8 pages, 2008.

[15] H. Endo, T. Yamashita, and T. Sugiura, "A high-power-factor buck converter," in PESC '92 Record. 23rd Annual IEEE Power Electronics Specialists Conference, pp. 1071-1076, Toledo, Spain, 1992.

[16] K. K. A. Devi, N. M. Din, and C. K. Chakrabarty, "Optimization of the voltage doubler stages in an rf-dc convertor module for energy harvesting," Circuits and Systems, vol. 3, no. 3, pp. 216-222, 2012.

[17] T. R. Ansari, A. Khan, and I. Ansari, "Wireless charging of mobile battery via optimization of RF energy harvesting system," International Journal of Scientific \& Engineering Research, vol. 6, no. 7, pp. 942-949, 2015.

[18] M. Park and I.-K. Yu, "A study on the optimal voltage for mppt obtained by surface temperature of solar cell," in 30th Annual Conference of IEEE Industrial Electronics Society, 2004. IECON 2004, vol. 3, pp. 2040-2045, Busan, South Korea, 2004.

[19] G. Walker et al., "Evaluating mppt converter topologies using a matlab pv model," Journal of Electrical \& Electronics Engineering, Australia, vol. 21, no. 1, p. 49, 2001.

[20] J. L. Santos, F. Antunes, A. Chehab, and C. Cruz, "A maximum power point tracker for $\mathrm{pv}$ systems using a high performance boost converter," Solar Energy, vol. 80, no. 7, pp. 772-778, 2006. 